\title{
Fibroid arising in a mullerian duct remnant presenting as a pelvic mass-sonographic diagnosis with magnetic resonance imaging correlation
}

\author{
Amandeep Singh*, Gauravdeep Singh
}

Sri Guru Ram Das Institute of Medical Sciences and Research, Amritsar, Punjab, India

Received: 18 September 2020

Revised: 01 November 2020

Accepted: 02 November 2020

\section{*Correspondence:}

Dr. Amandeep Singh,

E-mail: dr.amancs@gmail.com

Copyright: (c) the author(s), publisher and licensee Medip Academy. This is an open-access article distributed under the terms of the Creative Commons Attribution Non-Commercial License, which permits unrestricted non-commercial use, distribution, and reproduction in any medium, provided the original work is properly cited.

\section{ABSTRACT}

Mullerian agenesis is a rare congenital anomaly characterized as aplasia or hypoplasia of uterus in women with normal development of secondary sex characteristics. Presence of leiomyoma in mullerian agenesis is very rare and only few cases have been reported in the literature. Ultrasound and MRI showed a large soft tissue mass in right adnexal region. A provisional diagnosis of mullerian agenesis associated with two pelvic masses was made. Histopathology confirmed the diagnosis of leiomyoma.

Keywords: Mullerian agenesis, Fibroid, Primary amenorrhoea

\section{INTRODUCTION}

Mullerian agenesis is a rare congenital anomaly characterized as aplasia or hypoplasia of uterus in women with normal development of secondary sex characteristics. It affects 1 in 4000-5000 female births. It is a cause of primary amenorrhoea; second in frequency only to gonadal dysgenesis.

Presence of leiomyoma in mullerian agenesis is very rare and only few cases have been reported in the literature. Here we report a patient of mullerian agenesis with large leiomyoma originating from both horns of rudimentary uterus.

\section{CASE REPORT}

A 35-year-old married nullipara presented with a large pelvic mass. She had noticed a lump in the abdomen for the past 2 years. She gave a vague history of menarche and irregular and scanty menstruation.
Physical examination revealed normal bilateral breasts, normal axillary and pubic hair patterns. External genitalia were normal. Her height was $152 \mathrm{~cm}$ and weight $48 \mathrm{~kg}$. Thyroid was not enlarged. There was no galactorrhea.

On abdominal examination, she was found to have a $20 \times 15 \mathrm{~cm}$ mass arising from the pelvis. The mass was irregular, mobile, non-tender and was occupying most of the right iliac fossa and hypogastric region. There was no free fluid in the abdomen. She did not have hepatosplenomegaly.

The external genitalia were normal. Speculum examination revealed a blind $4 \mathrm{~cm}$ deep vaginal pouch and absent cervix. The investigations revealed a normal intravenous pyelogram and a chromatin positive buccal smear.

Hormonal profile showed serum follicle stimulating hormone (FSH) $5.4 \mathrm{mIU} / \mathrm{ml}$; serum leutenizing hormone (LH) $13.2 \mathrm{mIU} / \mathrm{ml}$; serum prolactin $15.9 \mathrm{ng} / \mathrm{mL}$ and CA$12519.3 \mathrm{IU} / \mathrm{ml}$. 
Trans- abdominal ultrasonography showed a large welldefined heterogenous mass in the pelvis extending into the lower abdomen. Uterus and ovaries could not be visualized separately from the mass on sonography (Figure 1).

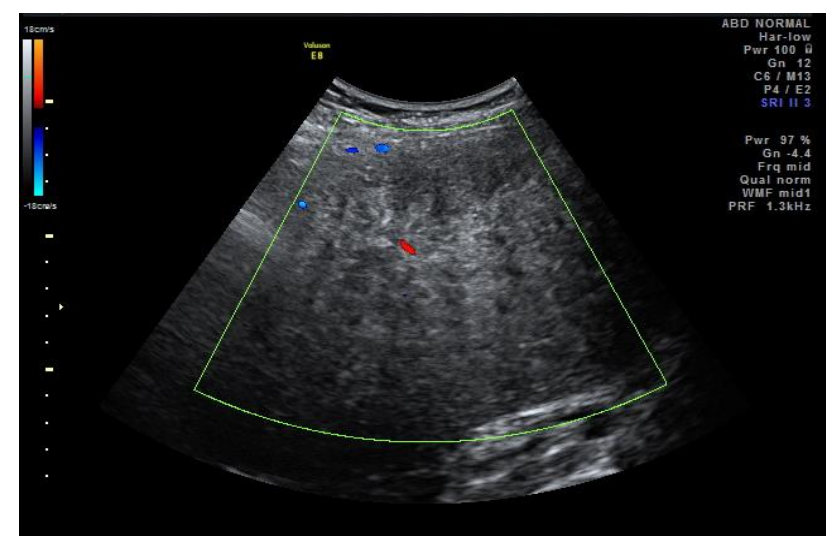

Figure 1: A large well-defined heterogeneous mass was seen in the pelvis extending into the lower abdomen showing minimal central vascularity on CFI.

On Magnetic resonance imaging, a large well-defined low signal intensity mass with few central high signal intensity areas was seen in right adnexal region on $\mathrm{T} 2 \mathrm{~W}$ TSE images. It measured $18.7 \times 14.2 \times 10 \mathrm{~cm}$ in size. Another small low to intermediate signal intensity mass measuring $4.7 \times 4 \times 3.3 \mathrm{~cm}$ in size was seen in left adnexal region. Only remnant of uterus was seen on MRI. Bilateral ovaries and fallopian tubes were also absent. (Figure 2-4).
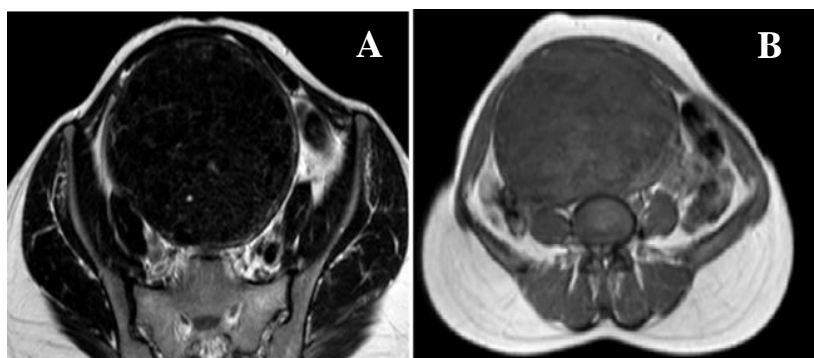

Figure 2: (A) T2W TSE and T1W TSE axial images shows a large relatively well-defined mass in the pelvis appearing hypointense on (B) T2W images and isointense on T1W images.

With a provisional diagnosis of mullerian agenesis associated with two pelvic masses, she was taken up for a laparotomy. On opening the abdomen through a midline vertical incision, small remnant of uterus was seen with a large mass arising from the right cornual horn of the rudimentary uterus and another small mass arising from left corneal horn. Both the pelvic masses along with rudimentary uterus were removed and were sent for histopathological examination. She had an uneventful recovery and was discharged on the 7 th postoperative day.

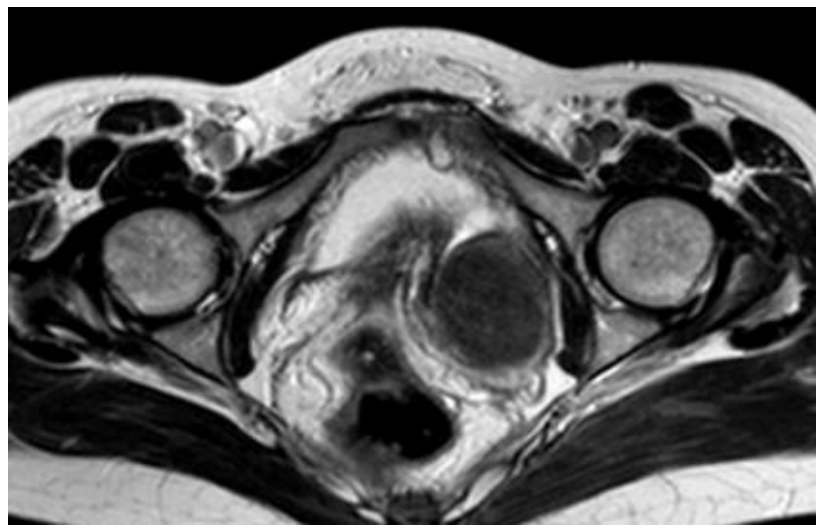

Figure 3: T2W TSE axial images shows a small low to intermediate signal intensity mass in left adnexal region.
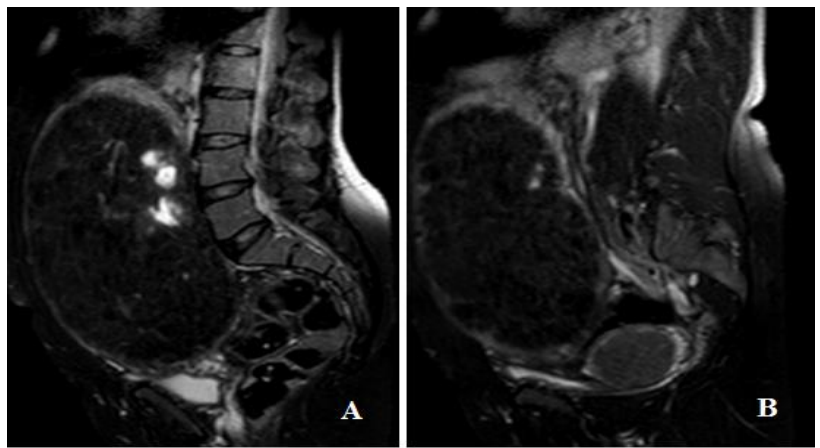

Figure 4: T2W SPAIR saggital images shows (A) large well-defined low intensity masses with few central hyperintense areas as shown by the arrow suggesting central cystic degeneration $(B)$ both the pelvis masses.

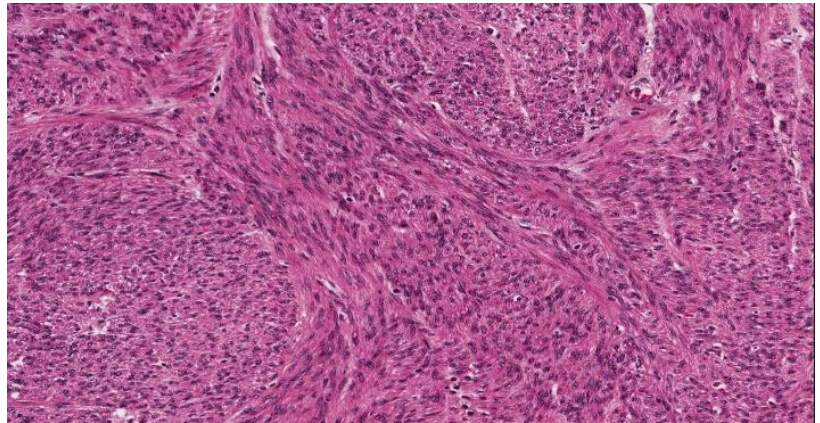

Figure 5: Histopathogy slide showed mutiple whorls of spindle shaped cells.

On gross examination of the histopathology specimen shows a large globular soft tissue mass measuring $20 \times 15 \times 10 \mathrm{~cm}$. On one side it was attached to fallopian tube along with ovary measuring $5 \times 2.5 \times 0.5 \mathrm{~cm}$ in size with fallopian tube measuring $5 \mathrm{~cm}$ in length. Cut section of ovary is partly solid partly cystic. Other side shows nodular projection measuring $5 \times 3.5 \times 1 \mathrm{~cm}$ in size. On cut 
section of globular soft tissue mass are seen areas of hemorrhage, necrosis and solid areas showing whorled appearance. Cut section of the nodular projection is grey white and shows whorled appearance.

Histological examination revealed dissecting bundles of spindle shaped cells s/o leiomyoma (Figure 5).

\section{DISCUSSION}

Mullerian agenesis is a rare disorder described as aplasia or hypoplasia of uterus and vagina due to early arrest in development of Mullerian duct. The incidence reported is one in 4000-5000 female births. ${ }^{1}$ Mullerian agenesis is the second most common cause of primary amenorrhoea after gonadal dysgenesis. Women with this syndrome are characterized by presence of $46 \mathrm{XX}$ karyotype, normal female secondary sex characters, normal ovarian functions and underdeveloped vagina. ${ }^{2}$ In addition, women with Mullerian agenesis may have renal, skeletal, hearing and cardiac anomalies., , $^{3,4}$

Presence of leiomyoma in mullerian agenesis is very rare and only few cases have been reported in the literature. Here we report a patient of mullerian agenesis with a large leiomyoma originating from the rudimentary uterus.

The female reproductive system develops from two embryologic structures-mullerian ducts and urogenital sinus (UGS). The mullerian ducts are mesodermal in origin and UGS is endodermal in origin. The development of the urinary system is closely related to the reproductive system; hence its anomalies are also associated with reproductive system abnormalities. ${ }^{3}$ Both male and female embryos, at 6 weeks of development, have two sets of paired genital ducts- the paramesonephric (mullerian) ducts (PMDs) and the mesonephric (wolffian) ducts (MDs). The paired PMDs, initially separated by a septum, fuse and form a Y-shaped structure, uterovaginal primordium (UVP). The UVP and UGS thereafter differentiate to form the female reproductive system. ${ }^{5,6}$

Mullerian duct anomalies have been estimated to occur in approximately $3 \%$ of women. As many as $25 \%$ of women with Mullerian duct anomalies have reproductive problems as compared with only $10 \%$ of general female population. $^{7}$

The American fertility society (AFS) classification, based on uterine anomalies, is most commonly used to classify Mullerian duct anomalies. Anomalies of vagina, tubes and urinary tracts are described as associated malformations. This classification system comprises seven classes-I, uterine hypoplasia and agenesis; II, unicornuate uterus; III, uterus didelphys; IV, bicornuate uterus; V, septate uterus; VI, arcuate uterus; VII, diethylstilbestrol (DES)-related anomalies. ${ }^{8}$
Incidence of leiomyoma of uterus is very high in the general female population. But only few cases of leiomyoma have been reported in women with mullerian agenesis. Beechman et al reported the first case of myoma in association with Mayer Rokitansky Kuster Hauser syndrome in $1977 .{ }^{9}$ Baker et al reported another case of fibroid arising in a mullerian duct remnant and presenting as a pelvic mass in a patient with vaginal agenesis. $^{10}$

Hsu et al described a case of mullerian duct leiomyoma, which was misdiagnosed as ovarian neoplasm, and after surgical removal and histopathology proved to be fibroid. ${ }^{11}$

In 2012, Fletcher et al reported two cases of mullerian duct remnant leiomyoma with Mayer Rokitansky Kuster Hauser syndrome; first case presented with acute abdominal pain and found to have a twisted adnexal mass alongwith a mullerian remnant leiomyoma. ${ }^{12}$

Recently Rawat et al reported a case of large leiomyoma in a woman with Mayer Rokitansky Kuster Hauser syndrome. ${ }^{13}$

There are only 12 such reported cases in the existing medical literature.

The etiopathogenesis of leiomyoma from smooth muscle cells of normal uterus is not known. Their growth has been associated with genetic predisposition, hormones and few growth factors. Leiomyomas of uterus are estrogen dependent tumours. As the proximal ends of mullerian ducts have smooth muscles, the presence of myoma in a case of mullerian agenesis is a theoretical possibility. The possible reason for this uncommon occurrence could be a decreased concentration or sensitivity of the estrogen receptors or a lesser genetic predisposition for the clonal chromosomal abnormalities that are observed in women with normal uterus with leiomyomas. ${ }^{14,15}$ However, the exact etiopathogenesis of leiomyoma from the rudimentary uterus in mullerian agenesis is not known

Diagnosis of Mullerian agenesis is delayed till late puberty. In Mullerian agenesis patients usually complain of primary amenorrhea, infertility and pelvic pain. First diagnostic modality is USG in such patients. On USG examination, leiomyomas are hypoechoic or heterogeneous masses. Cystic component with internal echogenic material may be seen in the leiomyomas due to cystic degeneration with necrosis or haemorrhage, like in our case. Calcifications may be seen as hyperechoic foci. Uterus and ovaries may not be seen in patients with a large pelvic mass. CT and MRI are very useful in the diagnosis of mullerian agenesis with leiomyoma and in providing road-map for surgery, latter being very sensitive and specific. On computed tomography (CT), leiomyomas are well circumscribed masses iso- to hypodense to myometrium and show variable 
enhancement patterns. Cystic areas and calcifications may be seen. MRI has nearly $100 \%$ accuracy in diagnosis of mullerian duct anomalies because of its excellent soft tissue resolution. ${ }^{16}$ Uterus and vagina are best evaluated on T2-weighted sagittal and axial MR images.

However, diagnostic laparoscopy is the gold standard for definitive diagnosis of mullerian agenesis. ${ }^{17} \mathrm{MRI}$ is also very useful and accurate in diagnosis and characterization of pelvic masses. On MRI, leiomyomas show low to intermediate signal intensity compared to myometrium on $\mathrm{T} 1$ and T2-weighted images. Cystic areas are hyperintense on T2-weighted image.

Differential diagnosis of leiomyoma of rudimentary uterus in mullerian agenesis includes ovarian fibroma, gastrointestinal stromal tumour (GIST) of intestine and extravesical leiomyoma of urinary bladder.

Treatment for patients of mullerian agenesis with leiomyoma is myomectomy or hysterectomy and vaginal reconstruction (vaginoplasty).

Psychological counselling is important to emphasize the fertility potential, though most patients may never become pregnant, but still they can become a mother with surrogate pregnancy.

\section{CONCLUSION}

In this case report, we described a case of mullerian agenesis with leiomyoma originating from both horns of rudimentary uterus and role of imaging in diagnosis and planning of surgery.

\section{Funding: No funding sources}

Conflict of interest: None declared

Ethical approval: Not required

\section{REFERENCES}

1. Caprart V, Gallelogo M. Vaginal agenesis. Am J Obstet Gynecol. 1976;124(1):98-107.

2. Morcel K, Guerrier D, Watrin T, Pellerin I, Leveque J. The Mayer-Rokitansky-Kuster-Hauser (MRKH) syndrome: clinical description and genetics. J Gynecol Obstet Biol Reprod. 2008;37(6):539-46.

3. Breech LL, Laufer MR. Mullerian anomalies. Obstet Gynecol Clin North Am. 2009;36(1):47-68.

4. Strübbe EH, Lemmens JA, Thijn CJ, Willemsen WN, van Toor BS. Spinal abnormalities and the atypical form of the Mayer-Rokitansky-KüsterHauser syndrome. Skelet Rradiol. 1992;21(7):459-62.
5. Moore KL, Persaud TV. The Developing Humen: Clinically Oriented Embryology. 6th ed. Philadelphia, Pa: WB Saunders Co. The urogenital system; the development of genital system. 1998:303

6. Rock JA, Baramki TA, Parmley TH, Jones Jr HW. A unilateral functioning uterine anlage with Müllerian duct agenesis. Int $\mathbf{J}$ Gynecol Obstet. 1980;18(2):99-101.

7. Troiano RN, McCarthy SM. Mullerian duct anomalies: imaging and clinical issues. Radiology. 2004;233(1):19-34.

8. The American Fertility Society classification of adnexal adhesions, distal tubal occlusion, tubal occlusion secondary to tubal ligation, tubal pregnancies, mullerian anomalies and intrauterine adhesions. Fertil Steril. 1988;49(6):944-55.

9. Beecham CT, Skiendzielewski J. Myoma in association with Mayer-Rokitansky-Kuster syndrome. Am J Obstet Gynecol. 1977;129:346

10. Baker J, Buttini M. Fibroid arising in a müllerian duct remnant and presenting as a pelvic mass in a patient with vaginal agenesis: an unusual finding. Aust N Z J Obstet Gynaecol. 1995;35(3):340-1.

11. Hsu SC, Tsai EM, Wu CH, Lee JN. A mullerian duct remnant myoma misdiagnosed as ovarian cancer in a woman with vaginal agenesis--a case report. Kaohs J Med Sci. 1999;15(2):110-2.

12. 12. Fletcher HM, Campbell-Simpson K, Walcott D, Harriott J. Müllerian remnant leiomyomas in women with Mayer-Rokitansky-Küster-Hauser syndrome. Obstet Gynecol. 2012;119:483-5.

13. Rawat KS, Buxi TBS, Yadav A, Ghuman SS, Dhawan S. Large leiomyoma in a woman with Mayer-Rokitansky-Kuster-Hauser syndrome. J Radiol Case Rep. 2013;7(3):39-46.

14. Rock JA, Baramki TA, Parmley TH, Jones Jr HW. A unilateral functioning uterine anlage with Müllerian duct agenesis. Int J Gynecol Obstet. 1980;18(2):99101.

15. Barbieri RL, Friedman AJ, Pavelka K, Fletcher JA, Morton CC, Rein MS. Cytogenetic Abnormalities In Uterine Leiomyomata. Obstet Gynecol. 1991;77(6):923-6.

16. Mueller GC, Hussain HK, Smith YR, Quint EH, Carlos RC, Johnson TD, et al. Mullerian duct anomalies: comparison of MRI diagnosis and clinical diagnosis. Am J Roentgenol. 2007;189(6):1294-302.

17. Fiaschetti V, Taglieri A, Gisone V, Coco I, Simonetti G. Mayer-Rokitansky-Kuster-Hauser syndrome diagnosed by magnetic resonance imaging. Role of imaging to identify and evaluate the uncommon variation in development of the female genital tract. J Radiol Case Rep. 2012;6(4):17-24.

Cite this article as: Singh A, Singh G. Fibroid arising in a mullerian duct remnant presenting as a pelvic mass-sonographic diagnosis with magnetic resonance imaging correlation. Int J Reprod Contracept Obstet Gynecol 2020;9:5159-62. 